\title{
CRESCIMENTO, FENOLOGIA E PRODUTIVIDADE DE CULTIVARES DE MANDIOCA ${ }^{1}$
}

\author{
Amarílis Beraldo Rós ${ }^{2}$, Andréia Cristina Silva Hirata ${ }^{2}$, Humberto Sampaio de Araújo ${ }^{2}$, Nobuyoshi Narita ${ }^{2}$
}

\begin{abstract}
CASSAVA CULTIVARS

GROWTH, PHENOLOGY AND YIELD

Cassava is cultivated in all Brazilian States, what demands specific information about the most used cultivars. In this study, nine cassava cultivars for industry (IAC 12, IAC 13, IAC 14, IAC 15, Roxinha, Fibra, Fécula Branca, Branca de Santa Catarina, and Espeto) were evaluated, concerning growth and phenological attributes, as well as roots yield. The experimental design was randomized blocks, with four replications. IAC 14 was the highest cultivar, while IAC 15, Fécula Branca, and Espeto were the smallest ones. Fécula Branca and Espeto presented just one stem per plant. Branching was present in all cultivars, except for Fibra, and at different times. Branca de Santa Catarina was the first one to bloom. IAC 14 showed higher roots yield than Branca de Santa Catarina, IAC 12, Fécula Branca, Espeto, IAC 13, and IAC 15. Roots dry matter for IAC 12 was higher than for Roxinha and Branca de Santa Catarina. The aerial part features differed among cultivars, while root number, individual mass, length, and diameter did not differ. Results showed that those cultivars presented different growth and phenological features, as well as different root yields.
\end{abstract}

KEY-WORDS: Manihot esculenta Crantz; branching; flowering; plant height; dry matter.

\section{INTRODUÇÃO}

A mandioca pertence à família Euphorbiaceae e caracteriza-se por ser planta tolerante a condições de seca e de baixa fertilidade do solo (Dias et al. 1997). É uma planta de origem brasileira (Carvalho 2005) e sua importância econômica está na produção de raízes tuberosas e feculentas, que representam valioso alimento para consumo humano e animal, sendo, ainda, opção para a produção de energia renovável - etanol ou álcool etílico (Conceição 1981). Sua parte aérea também apresenta elevado potencial para a alimentação animal (Modesto et al. 2004).

\section{RESUMO}

A mandioca é cultivada em todos os Estados brasileiros e isto demanda a obtenção de informações específicas a respeito das cultivares mais utilizadas. Neste estudo, nove cultivares de mandioca para indústria (IAC 12, IAC 13, IAC 14, IAC 15, Roxinha, Fibra, Fécula Branca, Branca de Santa Catarina e Espeto) foram avaliadas, quanto a características de crescimento e de fenologia e quanto à produtividade de raízes. O delineamento experimental foi em blocos ao acaso, com quatro repetições. IAC 14 apresentou o maior porte, enquanto IAC 15, Fécula Branca e Espeto, os menores. Fécula Branca e Espeto apresentaram apenas uma haste por planta. A ramificação de hastes ocorreu em todas as cultivares, com exceção de Fibra, e em diferentes épocas. Branca de Santa Catarina foi a primeira a florescer. IAC 14 apresentou produtividade de raízes superior a Branca de Santa Catarina, IAC 12, Fécula Branca, Espeto, IAC 13 e IAC 15. A massa seca de raízes de IAC 12 foi superior a Roxinha e Branca de Santa Catarina. Características relacionadas à parte aérea diferiram entre as cultivares, enquanto número, massa individual, comprimento e diâmetro de raízes não diferiram. Os resultados permitiram concluir que as cultivares estudadas apresentaram distintas características fenológicas e de crescimento, bem como diferentes produtividades de raiz.

PALAVRAS-CHAVE: Manihot esculenta Crantz; ramificação; floração; porte de planta; massa seca.

A mandioca é cultivada em todos os Estados brasileiros (IBGE 2011) e diversas cultivares são utilizadas, fato que demanda a obtenção de informações específicas a respeito daquelas mais populares, tais como espaçamento entre plantas, materiais adequados ao plantio mecanizado e cultivares com elevada produtividade.

O conhecimento da fenologia de uma planta pode ajudar no planejamento e no manejo do plantio (Falcão et al. 2003). Assim, o estudo fenológico é importante para o estabelecimento de relações entre o comportamento da planta e determinadas condições ambientais, como temperatura e umidade, sendo que 
o conhecimento das características de crescimento contribui para o estabelecimento de critérios técnicos para a definição do espaçamento entre plantas, possibilidade de plantio mecanizado e período crítico de interferência de plantas infestantes.

O objetivo deste trabalho foi avaliar o crescimento, fenologia e produtividade de nove cultivares de mandioca, destinadas às indústrias de amido e farinha.

\section{MATERIAL E MÉTODOS}

O estudo foi realizado na Agência Paulista de Tecnologia dos Agronegócios, Pólo Alta Sorocabana, no município de Presidente Prudente, SP (22 ${ }^{\circ} 11^{\prime}$ S, $51^{\circ} 23^{\prime} \mathrm{W}$ e 424,29 $\mathrm{m}$ de altitude). O clima é classificado como Aw, apresentando duas estações bem definidas: verão quente e úmido e inverno ameno e seco. Segundo dados da estação meteorológica da Faculdade de Ciências e Tecnologia da Universidade Estadual Paulista (apud Golla 2006), a temperatura média anual é de $23,0^{\circ} \mathrm{C}$, sendo que a temperatura média do mês mais frio (julho) é de $19,5^{\circ} \mathrm{C}$ e a do mês mais quente (fevereiro) de $25,5^{\circ} \mathrm{C}$. A precipitação média anual é de $1.287,7 \mathrm{~mm}$ e, de novembro a fevereiro, ocorrem as maiores precipitações pluviométricas. A temperatura média mensal e a precipitação mensal ocorridas durante o período do experimento são apresentadas na Figura 1.

Nove cultivares de mandioca para indústria foram avaliadas: IAC 12, IAC 13, IAC 14, IAC 15, Roxinha, Fibra, Fécula Branca, Branca de Santa Catarina e Espeto (Clones PRDTAAS 01, PRDTAAS 02, PRDTAAS 03, PRDTAAS 04, PRDTAAS 05, PRDTAAS 06, PRDTAAS 07, PRDTAAS 08 e

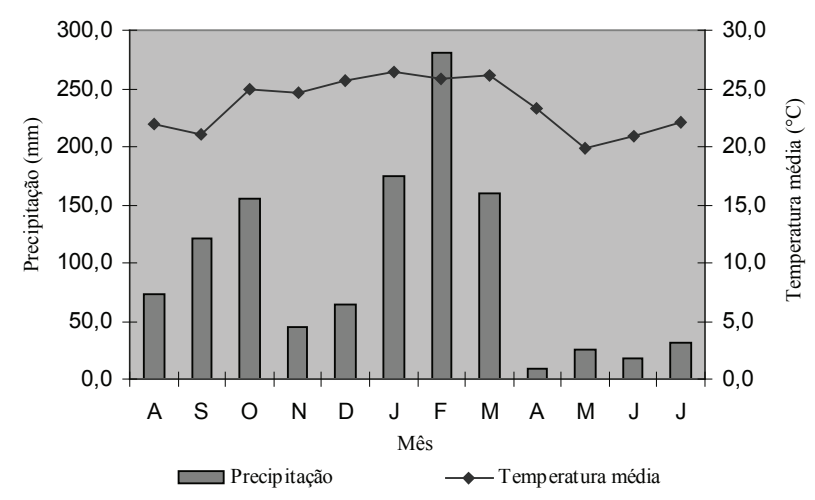

Figura 1. Precipitação e temperatura média mensal, entre agosto de 2005 e julho de 2006 (Presidente Prudente, SP).
PRDTAAS 09, respectivamente). Foram retiradas manivas (material de plantio) com $20,0 \mathrm{~cm}$ de comprimento, obtidas do terço médio de hastes de plantas com 12 meses de idade. As manivas foram plantadas a $10,0 \mathrm{~cm}$ de profundidade, em Argissolo Vermelho-Amarelo, com as seguintes características químicas: $\mathrm{pH}\left(\mathrm{CaCl}_{2}\right)=5,3 ; \mathrm{P}$ (resina) $=19 \mathrm{mg} \mathrm{dm}^{-3} ; \mathrm{K}=$ $1,2 \mathrm{mmol}_{\mathrm{c}} \mathrm{dm}^{-3} ; \mathrm{H}+\mathrm{Al}^{+3}=13 \mathrm{mmol}_{\mathrm{c}} \mathrm{dm}^{-3} ; \mathrm{Ca}^{+2}=$ $10 \mathrm{mmol}_{\mathrm{c}} \mathrm{dm}^{-3} ; \mathrm{Mg}^{+2}=7 \mathrm{mmol}_{\mathrm{c}} \mathrm{dm}^{-3}$; matéria orgânica $=11 \mathrm{~g} \mathrm{dm}^{-3} ; \mathrm{e} \mathrm{V}(\%)=59$.

O delineamento experimental foi em blocos ao acaso, com quatro repetições. Cada unidade experimental compreendeu uma área de $40,0 \mathrm{~m}^{2}$, com quatro linhas, contendo 10 plantas cada, no espaçamento de $1,0 \mathrm{~m}$ x 1,0 m. Aárea útil constituiu-se das duas linhas centrais de cada parcela, excetuando-se as plantas das extremidades. A área experimental foi mantida sem a presença de plantas infestantes, por meio de capinas manuais, durante todo o ciclo da cultura.

O plantio foi realizado em $01 / 08 / 2005$, sendo coletados dados aos 80, 120, 160, 200, 240, 280 e 320 dias após o plantio (DAP). Para a avaliação da fenologia, também foram considerados os períodos de 100, 140 e 165 DAP. As características avaliadas foram: altura de plantas (medida a partir do nível do solo até o broto terminal), número de folhas (folhas totalmente abertas da haste mais alta, considerando-se, ainda, duas folhas fechadas), número de hastes (brotadas do solo), existência de ramificação de hastes e época de florescimento (inflorescência com mais de $2,0 \mathrm{~cm}$ de comprimento). Para as variáveis altura de plantas e números de hastes e de folhas, foram coletados dados ao acaso de cinco plantas da área útil. Para as características existência de ramificação de hastes e época de florescimento, avaliaram-se todas as plantas da área útil, considerando-se a característica quando $50 \%$ das plantas ou mais a apresentassem.

$\mathrm{Na}$ colheita, em 01/08/2006, foi verificado o estande final da área útil e separadas, ao acaso, três plantas inteiras de cada parcela, dividindo-as em parte aérea mais maniva-mãe e raízes. Foi avaliada a massa fresca média das duas porções, quantificando-se o número médio de raízes e massa fresca, comprimento e diâmetro médio de cada raiz. A produção de raízes destas plantas foi somada à produção das demais, obtendo-se a produtividade das cultivares. Para a obtenção da massa seca das raízes, a porção mediana de 30 raízes foi picada em cubos de, aproximadamente, $1,0 \mathrm{~cm}^{3}$ e, após homogeneização, foi coletado $1,0 \mathrm{~kg}$ de cada porção, correspondente a cada parcela. Cada 
porção foi colocada em saco de papel e mantida em estufa com circulação forçada de ar, a $60^{\circ} \mathrm{C}$, até atingir peso constante.

Os dados obtidos foram submetidos a análises de variância e as médias ajustadas a equações de regressão polinomial ou comparadas pelo teste Tukey, conforme a necessidade. Adotou-se $5 \%$ de probabilidade de erro. O programa estatístico utilizado foi o Sisvar 5.1 (Ferreira 2007).

\section{RESULTADOS E DISCUSSÃO}

Houve interação significativa entre cultivares e épocas de avaliação, para as características altura e número de folhas, enquanto, para número de hastes, houve diferença apenas entre as cultivares. $\mathrm{Na}$ característica altura de plantas, todas as cultivares apresentaram resposta estimada segundo modelo quadrático (Figura 2).

As cultivares apresentaram diferenças entre si, na altura de suas plantas, desde a primeira avaliação (80 DAP), época, na qual, Branca de Santa Catarina, com $35,0 \mathrm{~cm}$, apresentou quase o triplo da altura estimada para as plantas das cultivares Espeto e Fécula Branca $(13,0 \mathrm{~cm})$, cultivares que, juntamente com IAC 15, apresentaram o menor porte estimado, dentre as cultivares estudadas, ao final da avaliação, com
$175,0 \mathrm{~cm}, 173,0 \mathrm{~cm}$ e $176,0 \mathrm{~cm}$, respectivamente. A cultivar que apresentou maior crescimento em altura, durante o período avaliado, foi a IAC 14, com altura estimada em 20,0 cm, aos 80 DAP, atingindo altura estimada de $272,0 \mathrm{~cm}$, aos 320 DAP, sendo a cultivar de maior porte, a partir de 135 dias.

Aos 320 DAP, a sequência de cultivares de maior porte estimado absoluto, em ordem decrescente, foi: IAC 14, Branca de Santa Catarina, IAC 12, IAC 13, Fibra, Roxinha, IAC 15, Fécula Branca e Espeto. No entanto, Branca de Santa Catarina e IAC 12 não apresentaram diferença de altura expressiva entre si, o mesmo ocorrendo para IAC 15, Fécula Branca e Espeto. Vidigal Filho et al. (2000) compararam a altura de plantas das cultivares IAC 12, IAC 13, IAC 14, Fécula Branca, Espeto, Branca de Santa Catarina e Fibra e obtiveram resultados semelhantes.

O comportamento, em relação à altura, é um fator importante, tanto na competição com plantas infestantes quanto na escolha de cultivares para consorciação com outras culturas e definição de espaçamento adequado.

Houve interação significativa entre número de folhas da haste mais alta e época de avaliação. Todas as cultivares responderam segundo modelo quadrático e apresentaram número de folhas semelhante, até, aproximadamente, 95 DAP (Figura 3). A partir desta

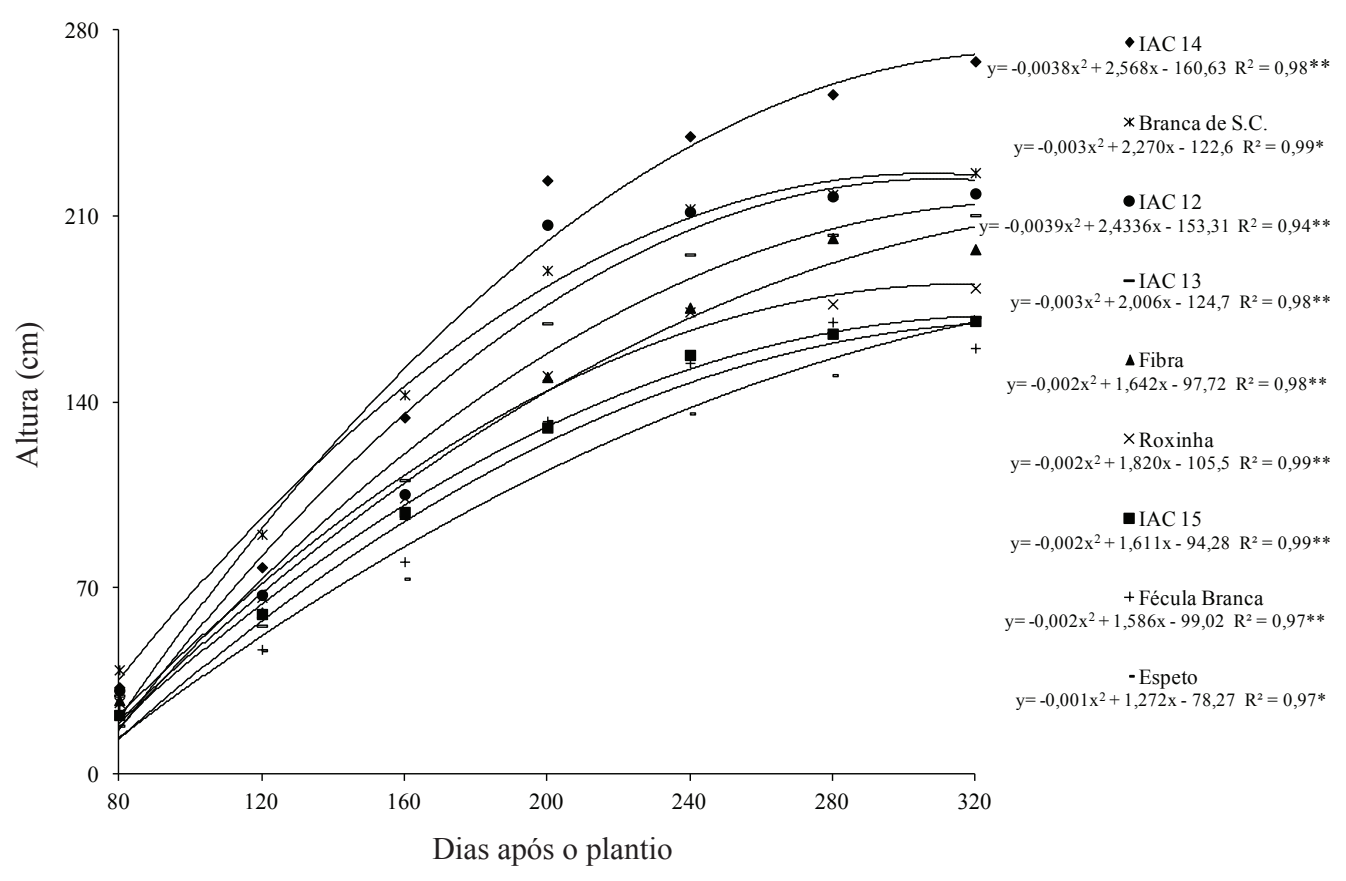

Figura 2. Altura de plantas de cultivares de mandioca, no período de 80 a 320 dias após o plantio (Presidente Prudente, SP, 2005/2006). * e **: Significativo a $5 \%$ e $1 \%$, respectivamente, pelo teste F. 


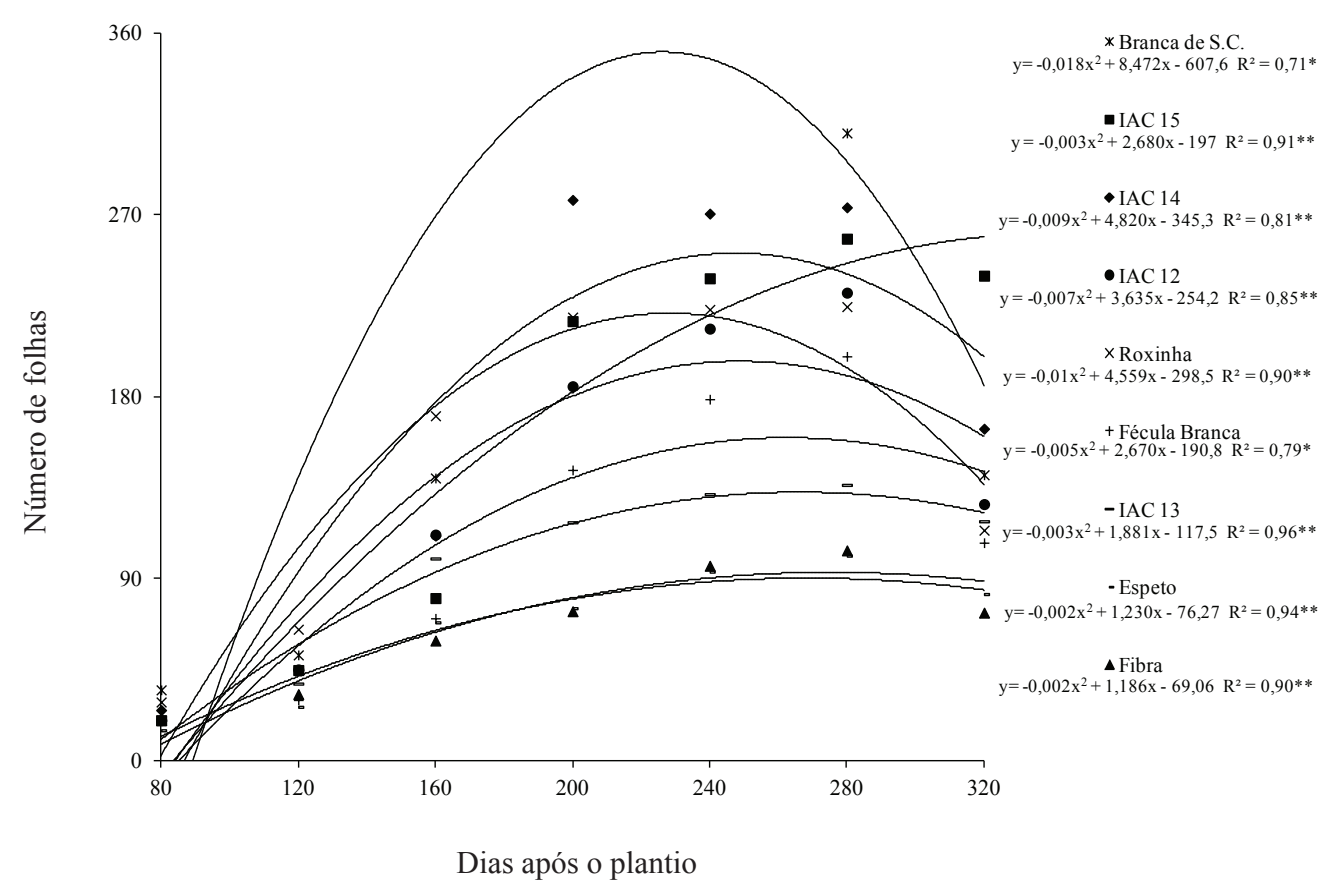

Figura 3. Número de folhas da haste mais alta, em plantas de cultivares de mandioca, no período de 80 a 320 dias após o plantio (Presidente Prudente, SP, 2005/2006). * e**: Significativo a 5\% e 1\%, respectivamente, pelo teste F.

data, a diferença na característica entre as cultivares foi sendo ampliada.

Branca de Santa Catarina atingiu o maior número de folhas, na haste principal, enquanto Fibra e Espeto apresentaram o menor valor da característica. O número de folhas, na haste principal, associa-se ao início da acumulação de amido nas raízes, conforme descreveram Schons et al. (2007), ao verificarem que a cultivar de mandioca RS 13 iniciou este acúmulo quando sua haste apresentava 21 folhas totalmente visíveis, independentemente da época de plantio. Desta forma, é possível que as cultivares que apresentaram maior número de folhas, nas coletas iniciais, tenham sido as primeiras a iniciar o processo de acumulação de amido nas raízes.

Durante o período avaliado, todas as cultivares, com exceção de IAC 15, apresentaram queda de folhas em época anterior à data da última coleta (320 DAP). Segundo os modelos estimados, as cultivares Branca de Santa Catarina, Roxinha, IAC 14 e IAC 12 iniciaram a queda de folhas em menor período de tempo (226, 228, 248 e 249 DAP, respectivamente), em relação às demais cultivares. Espeto, Fibra, IAC 13 e Fécula Branca foram as últimas a iniciarem a queda de suas folhas $(280,270,269$ e 262 DAP, respectivamente). Segundo o modelo estimado, a cultivar IAC 15 iniciaria queda de folhas a partir de 344 DAP.
A diminuição no número de folhas está relacionada à diminuição na taxa de emissão de folhas, nos meses mais frios, e à abscisão das folhas existentes (Peressin et al. 1998). Nas condições do Estado de São Paulo, pode ocorrer desfolha total das plantas, na época mais fria e seca do ano (Lorenzi et al. 1981).

Quanto à característica número de hastes de plantas, não houve interação significativa entre esta e as épocas de avaliação, mas houve diferença entre as cultivares (Figura 4). Fécula Branca e Espeto apresentaram apenas uma haste por planta, enquanto, nas demais cultivares, plantas com duas ou mais hastes foram frequentes.

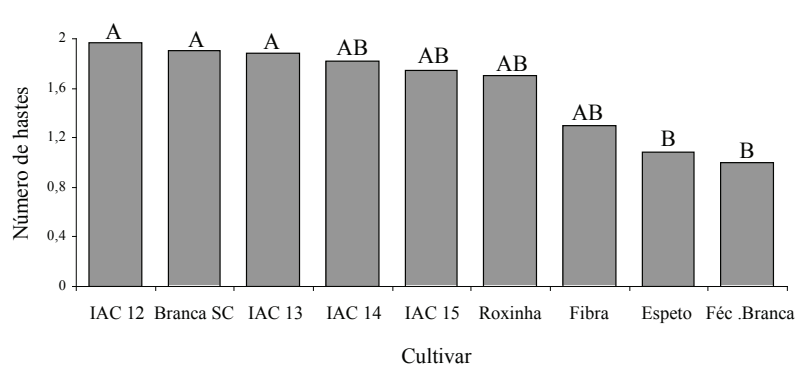

Figura 4. Número de hastes em plantas de cultivares de mandioca (Presidente Prudente, SP, 2005/2006). Médias seguidas por letras iguais não diferem significativamente pelo teste Tukey, a $5 \%$. 
A ramificação de hastes variou entre as cultivares. Houve ramificação da cultivar Roxinha aos 80 DAP, seguida por Branca de Santa Catarina, aos 100 DAP. As cultivares IAC 12, IAC 13, IAC 14, IAC 15 e Fécula Branca apresentaram ramificação aos 120 DAP, período em que Roxinha emitiu a segunda ramificação, em suas hastes já ramificadas. Aos 140 DAP, Branca de Santa Catarina também emitiu a segunda ramificação, enquanto Espeto, neste período, apresentou a primeira e única ramificação. A cultivar Fibra não ramificou.

Segundo Irolivea et al. (1998), cultivares com apenas uma haste e que não apresentam ramificações podem ser plantadas com menor espaçamento, o que eleva o rendimento e reduz o tempo para o fechamento da cultura, tanto na linha como na entrelinha, diminuindo custos com o controle de plantas infestantes, os quais representam cerca de $40 \%$ dos custos de produção da cultura da mandioca (Peressin \& Carvalho 2002) e podem reduzir, em até $90 \%$, a produtividade das raízes (Peressin et al. 1998).

Cultivares de uma haste e que se ramificam podem apresentar menor rendimento, em espaçamentos mais adensados, pois necessitam de maior espaço para desenvolver suas ramas e, consequentemente, expressar seu potencial de produção de fotoassimilados. A característica ramificação influencia a mecanização da cultura. As ramas da cultivar Fibra, único material estudado a não apresentar ramificação de hastes, caracterizaram-se como adequadas à prática de plantio mecanizado, por não apresentarem ramificações e serem compridas.

A época de florescimento foi distinta entre as cultivares. Branca de Santa Catarina foi a primeira a florescer (100 DAP). As cultivares IAC 15, IAC 14, IAC 13, IAC 12, Roxinha e Fécula Branca apresentaram inflorescência aos 120 DAP. Espeto floresceu somente aos 140 DAP, período em que Branca de Santa Catarina floresceu novamente. Roxinha apresentou a segunda fase de florescimento aos 165 DAP e Fibra não floresceu. Embora a mandioca venha sendo propagada vegetativamente, a reprodução sexuada é ativa, possibilitando a melhoristas trabalharem com suas sementes (Silva et al. 2001).

Quanto ao estande final, em todas as cultivares, exceto Fécula Branca, a população de plantas foi superior a $90 \%$, em relação ao número de manivas plantadas, e, nas características avaliadas na colheita, houve diferença entre as cultivares apenas quanto à massa da parte aérea das plantas mais maniva-mãe (Tabela 1).

Quanto à massa fresca da parte aérea mais a maniva-mãe, observou-se que as cultivares Espeto e Fécula Branca apresentaram as menores produções (Tabela 1), pois a maioria de suas plantas caracterizou-se apenas por uma haste, além do baixo porte. As demais cultivares não diferiram entre si, quanto à massa da parte aérea, ainda que Sagrilo et al. (2002) tenham verificado que a massa da parte aérea (considerada a partir de $0,10 \mathrm{~m}$ da superfície do solo) da cultivar IAC 14 foi superior à da IAC 13.

A massa da parte aérea é importante, quando se associam a produção de raízes para consumo humano e a produção da parte aérea para a alimentação animal, pois constitui excelente substituto para porções de cereais utilizados em rações (Ferreira Filho et al. 2007). Embora a qualidade varie entre cultivares, é viável alimentar ruminantes com silagem da parte

Tabela 1. Características avaliadas em cultivares de mandioca, na época da colheita (Presidente Prudente, SP, 2006).

\begin{tabular}{|c|c|c|c|c|c|c|c|}
\hline \multirow{3}{*}{ Cultivar } & \multicolumn{7}{|c|}{ Característica } \\
\hline & \multirow{2}{*}{$\begin{array}{c}\mathrm{EF} \\
\%\end{array}$} & \multirow{2}{*}{$\begin{array}{l}\text { NR } \\
\text { un. }\end{array}$} & MPA & MFR & MFIR & $\mathrm{CR}$ & DR \\
\hline & & & \multicolumn{3}{|c|}{$\mathrm{kg}-$} & \multicolumn{2}{|c|}{$\mathrm{cm}$} \\
\hline IAC 14 & 97 & $8,8 \mathrm{~A}$ & $4,6 \mathrm{~A}^{1}$ & $4,1 \mathrm{~A}$ & $0,53 \mathrm{~A}$ & $22,5 \mathrm{~A}$ & $5,6 \mathrm{~A}$ \\
\hline Fibra & 91 & $7,3 \mathrm{~A}$ & $2,5 \mathrm{~A}$ & $3,7 \mathrm{~A}$ & $0,51 \mathrm{~A}$ & $25,7 \mathrm{~A}$ & $5,3 \mathrm{~A}$ \\
\hline Roxinha & 97 & $7,8 \mathrm{~A}$ & $2,7 \mathrm{~A}$ & $3,6 \mathrm{~A}$ & $0,48 \mathrm{~A}$ & $24,1 \mathrm{~A}$ & $5,3 \mathrm{~A}$ \\
\hline Branca de Santa Catarina & 94 & $8,5 \mathrm{~A}$ & $4,4 \mathrm{~A}$ & $5,0 \mathrm{~A}$ & $0,59 \mathrm{~A}$ & $23,5 \mathrm{~A}$ & $5,9 \mathrm{~A}$ \\
\hline IAC 12 & 94 & $7,0 \mathrm{~A}$ & $3,8 \mathrm{~A}$ & $5,3 \mathrm{~A}$ & $0,41 \mathrm{~A}$ & $26,3 \mathrm{~A}$ & $4,8 \mathrm{~A}$ \\
\hline Fécula Branca & 88 & $6,0 \mathrm{~A}$ & $1,5 \mathrm{~B}$ & $3,9 \mathrm{~A}$ & $0,65 \mathrm{~A}$ & $28,0 \mathrm{~A}$ & $5,3 \mathrm{~A}$ \\
\hline Espeto & 96 & $8,4 \mathrm{~A}$ & $1,9 \mathrm{~B}$ & $3,8 \mathrm{~A}$ & $0,45 \mathrm{~A}$ & $24,8 \mathrm{~A}$ & $5,3 \mathrm{~A}$ \\
\hline IAC 13 & 99 & $7,7 \mathrm{~A}$ & $3,2 \mathrm{~A}$ & $4,1 \mathrm{~A}$ & $0,53 \mathrm{~A}$ & $27,5 \mathrm{~A}$ & $5,3 \mathrm{~A}$ \\
\hline IAC 15 & 94 & $8,5 \mathrm{~A}$ & $4,2 \mathrm{~A}$ & $3,9 \mathrm{~A}$ & $0,47 \mathrm{~A}$ & $24,1 \mathrm{~A}$ & $5,4 \mathrm{~A}$ \\
\hline
\end{tabular}

${ }^{1}$ Médias seguidas da mesma letra, na coluna, não diferem entre si, pelo teste Tukey, a 5\%. EF: estande final; NR: número de raízes; MPA: massa da parte aérea + manivamãe; MFR: massa fresca das raízes; MFIR: massa fresca individual das raízes; CR: comprimento das raízes; DR: diâmetro das raízes. 
aérea de mandioca (Azevedo et al. 2006). O feno de ramas de mandioca também é opção para alimentação de equinos (Moretini et al. 2004) e coelhos (Scapinello et al. 2000).

Todas as cultivares apresentaram massa fresca de raízes por planta superior a $3,5 \mathrm{~kg}$, destacando-se Branca de Santa Catarina (5,0 kg) e IAC $12(5,3 \mathrm{~kg})$, embora estas cultivares não tenham diferido significativamente das demais. As características número, massa fresca individual, comprimento e diâmetro de raízes também não diferiram entre as cultivares (Tabela 1).

Houve diferença entre algumas cultivares, em relação à produtividade (Tabela 2 ). A produtividade da cultivar IAC 14, embora não tenha diferido estatisticamente de Fibra e Roxinha, as quais também produziram mais de 30 toneladas de raízes por hectare, foi superior às produtividades de Branca de Santa Catarina, IAC 12, Fécula Branca, Espeto, IAC 13 e IAC 15. Diferentemente, Sagrilo et al. (2002) não verificaram diferença de produtividade de raízes entre as cultivares IAC 14 e IAC 13.

Vidigal Filho et al. (2000), comparando a produtividade de IAC 12, IAC 13, IAC 14, Fécula Branca, Espeto, Branca de Santa Catarina e Fibra, verificaram maiores produtividades das cultivares Espeto, Fécula Branca e Fibra. Oliveira et al. (2007) não verificaram diferença significativa entre Espeto, Fécula Branca e Fibra, cultivadas sob manejo orgânico, assim como observado no presente trabalho, mas os autores observaram que as duas primeiras

Tabela 2. Produtividade e massa seca de raízes de cultivares de mandioca, na época da colheita (Presidente Prudente, SP, 2006).

\begin{tabular}{lcl}
\hline \multirow{2}{*}{ Cultivar } & Produtividade & Massa seca \\
\cline { 2 - 3 } & \multicolumn{1}{c}{$\mathrm{t} \mathrm{ha}^{-1}$} & \multicolumn{1}{c}{$\%$} \\
\hline IAC 14 & $36,8 \mathrm{~A}^{1}$ & $40,7 \mathrm{AB}$ \\
Fibra & $33,7 \mathrm{AB}$ & $40,3 \mathrm{AB}$ \\
Roxinha & $30,6 \mathrm{ABC}$ & $39,4 \mathrm{~B}$ \\
Branca de Santa Catarina & $28,9 \mathrm{BCD}$ & $39,3 \mathrm{~B}$ \\
IAC 12 & $27,3 \mathrm{BCD}$ & $44,0 \mathrm{~A}$ \\
Fécula Branca & $26,9 \mathrm{BCD}$ & $43,1 \mathrm{AB}$ \\
Espeto & $26,9 \mathrm{BCD}$ & $40,3 \mathrm{AB}$ \\
IAC 13 & $26,3 \mathrm{BCD}$ & $43,0 \mathrm{AB}$ \\
IAC 15 & $25,0 \mathrm{CD}$ & $40,2 \mathrm{AB}$ \\
\hline
\end{tabular}

${ }^{1}$ Médias seguidas da mesma letra, na coluna, não diferem entre si, pelo teste Tukey, a $5 \%$. apresentaram produtividade superior a IAC 15, enquanto Fibra se equiparou a esta última.

Quanto à massa seca das raízes (Tabela 2), verificou-se que IAC 12 foi superior, em relação às cultivares Roxinha e Branca de Santa Catarina, contudo, estes genótipos não diferiram das demais. Vidigal Filho et al. (2000) verificaram baixa matéria seca da cultivar Branca de Santa Catarina.

A percentagem de matéria seca de raízes, obtida em plantas com 12 meses, entre $39,3 \%$ e $44,0 \%$, foi superior à encontrada por Vidigal Filho et al. (2000), que realizaram a colheita das plantas aos 10 meses após a emergência. Tal fato pode estar relacionado ao aspecto relatado por Peressin et al. (1998), que verificaram acúmulo crescente de matéria seca nas raízes de mandioca, até a colheita.

\section{CONCLUSÕES}

1. As cultivares diferiram em altura de plantas, número de hastes e folhas e massa fresca da parte aérea mais a maniva-mãe.

2. Houve diferenças entre as cultivares avaliadas, quanto à presença ou ausência e época de ramificação de hastes.

3. As épocas e o número de fases de emissão de inflorescência foram distintos entre as cultivares.

4. A cultivar IAC 14 apresentou produtividade de raízes superior a Branca de Santa Catarina, IAC 12, Fécula Branca, Espeto, IAC 13 e IAC 15.

\section{REFERÊNCIAS}

AZEVEDO, E. B. de et al. Silagem da parte aérea de cultivares de mandioca. Ciência Rural, Santa Maria, v. 36, n. 6, p. 1902-1908, 2006.

CARVALHO, L. J. C. B. Biodiversidade e biotecnologia em mandioca (Manihot esculenta Crantz). Brasília, DF: Embrapa Recursos Genéticos e Biotecnologia, 2005.

CONCEIÇÃO, A. J. A mandioca. São Paulo: Nobel, 1981.

DIAS, C. A. C.; LOMGHI, A. A.; LORENZI, J. O. Mandioca. In: COORDENADORIA DE ASSISTÊNCIA TÉCNICA INTEGRAL. Manual técnico das culturas: cereais, fibrosas, leguminosas, oleaginosas, raízes e tubérculos, plantas tropicais, sacarinas. 2. ed. Campinas: CATI/SAA, 1997. p. 369-398.

FALCÃO, M. de A.; CLEMENT, C. R.; GOMES, J. B. M. Fenologia e produtividade da sorva (Couma utilis 
(Mart.) Muell. Arg.) na Amazônia Central. Acta Botanica Brasilica, Feira de Santana, v. 17, n. 4, p. 541-547, 2003.

FERREIRA, D. F. Sisvar: sistema de análise de variância para dados balanceados, versão 5.1. Lavras: DEX/ UFLa, 2007.

FERREIRA FILHO, J. R.; MATTOS, P. L. P. de; SILVA, J. da. Produção de biomassa de mandioca. In: CONGRESSO BRASILEIRO DE MANDIOCA, 12., 2007, Paranavaí. Anais... Paranavaí: Sociedade Brasileira de Mandioca, 2007. 1 CD-ROM.

GOLLA, A. B. Meio ambiente e agricultura na microbacia hidrográfica do córrego Palmitalzinho - Regente Feijó/São Paulo. 2006. 79 f. Dissertação (Mestrado em Geografia)Faculdade de Ciências e Tecnologia, Universidade Estadual de São Paulo, Presidente Prudente, 2006.

INSTITUTO BRASILEIRO DE GEOGRAFIA E ESTATÍSTICA (IBGE). Sistema IBGE de recuperação automática - SIDRA. 2011. Disponível em: <http://www. sidra.ibge.gov.br/>. Acesso em: 15 jun. 2011.

IROLIVEA, E. A. M. et al. Efeito do espaçamento entre plantas e da arquitetura varietal no comportamento vegetativo e produtivo da mandioca. Scientia Agricola, Piracicaba, v. 55, n. 2, p. 269-275, 1998.

LORENZI, J. O.; GALLO, J. R.; MALAVOLTA, E. Acumulação de matéria seca e macronutrientes por dois cultivares de mandioca. Bragantia, Campinas, v. 40, n. 14, p. $145-156,1981$

MODESTO, E. C. et al. Caracterização químicobromatológica da silagem do terço superior da rama de mandioca. Acta Scientiarum, Maringá, v. 26, n. 1, p. 136146, 2004.

MORETINI, C. A. et al. Avaliação nutricional de alguns alimentos para equinos por meio de ensaios metabólicos. Ciência e Agrotecnologia, Lavras, v. 28, n. 3, p. 621-626, 2004.
OLIVEIRA, A. de et al. Avaliação do potencial produtivo de mandioca industrial desenvolvida no sistema de produção orgânica em Campo Grande, MS. In: CONGRESSO BRASILEIRO DE MANDIOCA, 12., 2007, Paranavaí. Anais... Paranavaí: Sociedade Brasileira de Mandioca, 2007. 1 CD-ROM.

PERESSIN, V. A.; CARVALHO, J. E. B. de. Manejo integrado de plantas daninhas em mandioca. In: FUNDAÇÃO CARGILL. Culturas tuberosas amiláceas latino americanas. São Paulo: Fundação Cargill, 2002. p. 302-349.

PERESSIN, V. A. et al. Acúmulo de matéria seca na presença e na ausência de plantas infestantes no cultivar de mandioca SRT 59 - Branca de Santa Catarina. Bragantia, Campinas, v. 57, n. 1, p. 135-148, 1998.

SAGRILO, E. et al. Efeito da época de colheita no crescimento vegetativo, na produtividade e na qualidade de raízes de três cultivares de mandioca. Bragantia, Campinas, v. 61, n. 2, p. 115-125, 2002.

SCAPINELLO, C. et al. Desempenho de coelhos em crescimento alimentados com diferentes níveis de feno da rama da mandioca (Manihot esculenta Crantz). Ciência Rural, Santa Maria, v. 30, n. 3, p. 493-497, 2000.

SCHONS, A. et al. Emissão de folhas e início de acumulação de amido em raízes de uma variedade de mandioca em função da época de plantio. Ciência Rural, Santa Maria, v. 37, n. 6, p. 1586-1592, 2007.

SILVA, R. M. et al. Biologia reprodutiva de etnocultivares de mandioca. Scientia Agricola, Piracicaba, v. 58, n. 1, p. 101-107, 2001.

VIDIGAL FILHO, P. S. et al. Avaliação de cultivares de mandioca na região noroeste do Paraná. Bragantia, Campinas, v. 59, n. 1, p. 69-75, 2000. 